\title{
Conter de Troie et d'Alexandre, Études réunies par Laurence Harf-Lancner, Laurence Mathey-Maille et Michelle Szkilnik
}

\section{Maria Colombo Timelli}

\section{(2) OpenEdition Journals}

Édition électronique

URL : http://journals.openedition.org/studifrancesi/9423

DOI : $10.4000 /$ studifrancesi.9423

ISSN : 2421-5856

Éditeur

Rosenberg \& Sellier

\section{Édition imprimée}

Date de publication : 1 décembre 2007

Pagination : 624-625

ISSN : 0039-2944

\section{Référence électronique}

Maria Colombo Timelli, « Conter de Troie et d'Alexandre, Études réunies par Laurence Harf-Lancner, Laurence Mathey-Maille et Michelle Szkilnik », Studi Francesi [En ligne], 153 (LI | III) | 2007, mis en ligne le 30 novembre 2015, consulté le 10 janvier 2021. URL : http://journals.openedition.org/studifrancesi/ 9423 ; DOI : https://doi.org/10.4000/studifrancesi.9423

Ce document a été généré automatiquement le 10 janvier 2021.

\section{cc) $(9)$}

Studi Francesi è distribuita con Licenza Creative Commons Attribuzione - Non commerciale - Non opere derivate 4.0 Internazionale. 


\title{
Conter de Troie et d'Alexandre, Études réunies par Laurence Harf-Lancner, Laurence Mathey-Maille et Michelle Szkilnik
}

\author{
Maria Colombo Timelli
}

\section{RÉFÉRENCE}

Conter de Troie et d'Alexandre, Études réunies par Laurence HARF-LANCNER, Laurence MATHEY-MAILLE et Michelle SZKILNIK, Paris, Presses Sorbonne Nouvelle, 2006.

1 Ce volume contient les conférences présentées en 2004 et 2005 au Centre d'Études du Moyen Âge de l'Université de Paris 3. Les interventions s'organisent autour de la réception de la matière troyenne et de la construction du personnage littéraire d'Alexandre le Grand dans le Moyen Âge français.

2 L'Introduction, qui comprend quelques remarques d'Emmanuelle Baumgartner complétées par les réflexions de Laurence Harf, souligne comment la richesse et diversité de la matière d'Alexandre a fourni au Moyen Âge la possibilité d'une expérimentation de diverses formes littéraires, de l'histoire à la chanson épique au roman, et ce sur la longue durée, du xii ${ }^{\mathrm{e}}$ au $\mathrm{xv}^{\mathrm{e}}$ siècle: ce trajet, inauguré par les romans en vers d'Alexandre se dot en effet avec la biographie historique de Vasque de Lucène traduisant Quinte-Curce en 1468. Dans un article paru en 1998 en langue italienne, et publié ici en version française, la même Emmanuèle BAUMGARTNER (La formation du mythe d'Alexandre au XII siècle: le "Roman d'Alexandre" et l'exotisme, pp. 138-158) rappelle les étapes fondamentales de l'écriture du mythe d'Alexandre du xiie $a u x^{e}$ siècle, en suivant l'évolution formelle et le travail de réécriture mené par les clercs. Dans cette 'somme' s'impose d'abord la dimension guerrière, mais l'histoire d'Alexandre devient 
rapidement un 'miroir du prince', célébrant le guerrier, le conquérant, le fondateur de cités. Seule la dimension romanesque lui demeure étrangère.

Deux autres interventions sont centrées sur le dernier siècle du Moyen Âge, où le mythe d'Alexandre est encore très vivant, notamment en milieu bourguignon. La première est due à Sandrine HÉRICHÉ-PRADEAU: Une compilation à l'épreuve de l'invention: "Les Faicts et les Conquestes d'Alexandre le Grant" de Jehan Wauquelin, pp. 253-268. Après avoir indiqué les deux techniques que Jehan Wauquelin applique dans la réécriture de ses deux sources principales (réduction pour le Roman d'Alexandre en alexandrins vs. amplification de la source en prose, traduction française de l'Historia de Preliis, branche $\mathrm{J}^{2}$ ), S.H.-P. souligne la part d'originalité de l'écrivain bourguignon, capable de bien maîtriser l'ensemble de la matière et auteur au fond d'un roman 'original'. La seconde est consacrée au ms. Chantilly, Condé 651, richement illustré par 84 enluminures: Maud PEREZ-SIMON (Mise en scène du corps et discours politique dans un manuscrit du 'Roman d'Alexandre en prose' $d u x^{e}$ siècle, pp. 271-289) s'occupe de l'interprétation de 7 illustrations qui se séparent de la tradition iconographique du Roman d'Alexandre. Elle montre comment ces images orientent la lecture vers une réflexion d'ordre politique, et l'illustrateur fait d'Alexandre un modèle de roi.

Le volet consacré à la matière troyenne comprend un nombre plus important de communications.

5 Francine MORA-LEBRUN (D'une esthétique à l'autre: la parole féminine dans l'“liade" de Joseph d'Exéter et le "Roman de Troie" de Benoit de Sainte-Maure, pp. 31-50) rapproche deux réfections de l'Iliade, l'une en latin (Joseph d'Exéter, vers 1183-1190), l'autre en français (Benoît, même époque) en comparant deux catégories de parole: la parole pathétique (monologues et en particulier 'planctus') et la parole argumentée (essentiellement les dialogues visant à l'efficacité narrative); les traits communs aux deux auteurs portent sur la préférence accordée au pathétique et sur l'ambiguïté de la parole argumentée, rattachée d'une part à l'idée de la perversité du langage, d'autre part à celle de l'immoralité foncière des femmes dans la culture du temps.

Marie-Madeleine CASTELLANI ("Athis et Prophilias" et le "Roman de Troie", pp. 51-68) met en rapport les deux versions, brève et longue, d'Athis et Prophilias, avec les romans d'Antiquité. Pour ce faire, elle prend en compte tant les éléments internes au récit (par exemple la récurrence des personnages ou la citation des noms propres) que le contexte des manuscrits qui nous ont transmis Athis et Prophilias, pour conclure que les deux versions se rattachent pleinement au genre des romans antiques, au point de s'inscrire dans la continuité de la triade fondatrice (Troie, Thèbes, Enéas).

7 Liliane DULAC (Entre héroïsation et admonestation: la matière troyenne chez Christine de Pizan, pp. 91-113). La matière troyenne comporte chez Christine de Pizan deux volets: l'histoire de la ville et l'origine mythique de la monarchie française. L.D. étudie dans les œuvres composées entre la fin du xive siècle et 1407 (Epistre Othea, Mutacion de Fortune, Chemin de long estude, Fais et bonnes meurs du sage roy Charles V, Advision Cristine, Cité des Dames, Livre du corps de policie) les trois lectures auxquelles Christine soumet cette matière: historique, exemplaire, mythique.

8 Jean-Claude MÜHLETHALER (D'Énée à Jean de Saintré: l'idéal littéraire à l'épreuve de la cour, pp. 115-133) montre comment, en pratiquant une «écriture fragmentaire» (p. 131), Antoine de La Sale utilise l'Énéide comme un hypo-texte: les parallèles Énée / Saintré, Didon / 
Belle Cousine sont intégrés à la parodie et à la réflexion sur la fonction de la littérature dans la société.

Françoise VIEILlARD ( $\mathrm{Du}$ "Roman de Troie" à la 'vraie estoire de Troie' (Prose 1 version commune): le choix de l'Histoire, pp. 177-193). L'auteur de cette rédaction de Prose 1 prétend faire œuvre d'historien (cf. le Prologue); à partir de cette constatation, F.V. montre les caractéristiques fondamentales de ce récit: mise en place des personnages, des lieux, des données chronologiques, puis déroulement de l'histoire. L'auteur de Prose 1 suit assez fidèlement le modèle en vers, mais le soumet à une moralisation chrétienne, animé qu'il est par une vision théologique de l'Histoire.

Catherine CROIZY-NAQUET (Les 'Retours' dans le "Roman de Troie" de Benoît de Sainte-Maure et dans le "Roman de Troie" en prose, pp. 195-213) compare la section finale - les 'Retours', soit les événements qui adviennent après la chute de Troie - dans le roman de Benoît et dans la Prose 1. La vision pessimiste de l'Histoire dans le roman en vers semble s'estomper dans la réécriture en prose, où c'est le sens du progrès qui prime: l'Histoire en marche vers la Révélation.

11 Anna Maria BABBI (Stratigraphie intertextuelle entre Ovide et la matière troyenne: l'“Ovide moralisé", Livre XII, pp. 215-229) examine l'addition des Héroïdes xvi et xvii (Paris à Hélène et Hélène à Paris) dans le Livre XII de l'Ovide moralisé. Elle peut conclure que l'auteur du remaniement médiéval connaît et utilise d'autres textes classiques, en l'occurrence l'Ars amatoria. Elle montre en conclusion l'intérêt qu'il y aurait à reconsidérer l'Ovide moralisé au sein de la tradition européenne des Métamorphoses, dont on dénombre aussi des traductions en langue castillane, en italien et en allemand.

12 Marie JАСОВ (L'ekphrasis en images: métamorphoses de la description dans l'“Histoire de la destruction de Troye la Grant" enluminée par l'atelier des Colombe à la fin du xve siècle, BnF n.a.fr. 24920, pp. 138-158) consacre son étude aux illustrations du manuscrit unique de la tradition tardive de l'Historia de Guido delle Colonne. L'extrême concision du texte contraste fortement avec la richesse de détails dans les enluminures, pour lesquelles les Colombe ont dû s'inspirer d'autres sources. Ce manuscrit somptueux est un témoin privilégié de la mutation de la conception de l'image au seuil de la Renaissance, la page enluminée tendant à acquérir «l'autonomie du tableau de chevalet» (p. 308). 